\title{
A Practical Compensation Method for Differential Column Shortenings in High-rise Reinforced Concrete Buildings
}

\author{
Mutlu Secer ${ }^{1 *}$, Amanullah Zamani $^{1}$, Yalcin Isler ${ }^{2}$ \\ ${ }^{1}$ Department of Civil Engineering, Faculty of Engineering and Architecture, Izmir Katip Celebi University, 35620, Izmir, Turkey \\ 2 Department of Biomedical Engineering, Faculty of Engineering and Architecture, Izmir Katip Celebi University, 35620, Izmir, Turkey \\ * Corresponding author, e-mail: mutlu.secer@ikc.edu.tr
}

Received: 25 March 2020, Accepted: 05 October 2020, Published online: 04 November 2020

\begin{abstract}
High-rise reinforced concrete buildings have technical, economic and environmental advantages for high density development and they have become a distinctive feature for densely populated urban areas around the world. For this purpose, structural design of high-rise reinforced concrete buildings have become forward and particularly serviceability requirements gained more interest. Differential shortening of vertical members is one of the serviceability requirements; however, only a limited number of studies exist. In this study, a practical compensation method was proposed for the differential shortening of columns and shear walls in high-rise reinforced concrete buildings. In the proposed compensation method, vertical members were grouped and the total error was aimed to be minimized by penalizing the higher shortening differences in the groups to simplify the process of building construction. In order to validate the proposed method, a 32-storey high-rise building that was built in Izmir Turkey was investigated considering both the construction sequence and time-dependent effects as shrinkage and creep. Vertical shortening of columns and shear walls in the tower part of the building were calculated. Uniform-grouped compensation method and the proposed penalized errors compensation method with using L1-norm and L2-norm were applied for differential shortenings of columns and shear walls with considering different numbers of member groups. The magnitude of errors for each compensation method was presented and evaluated. Results of the numerical study reveal that the proposed penalized errors compensation method was capable of determining the compensation errors by minimizing the maximum errors efficiently.
\end{abstract}

\section{Keywords}

compensation, high-rise building, differential shortening, time-dependent analysis, construction sequence, shrinkage, creep

\section{Introduction}

The use of high-rise buildings has become necessary as a result of high-density and rapid urban development. High-rise buildings provide the opportunity to maximize the land use rate, create more living space for the increasing population, gain more rentable space, make the structure economically viable and control urban sprawl with their relatively small carbon footprint. Since the amount of steel, concrete, glass and other construction materials needed to construct a single high-rise building is large, economic and environmental impacts are substantial. Therefore, structural design and particularly serviceability requirements of high-rise buildings become forward. Serviceability requirements generally cover inter-storey drifts, top-storey lateral displacements, human or machine-induced floor vibrations, building accelerations caused by lateral dynamic excitations, differential shortenings of vertical members as a consequence of time-dependent effects. Among these serviceability conditions, the compensation of differential shortenings is an area in which the time-dependent structural behavior is significant and consequently a systematic approach has not been used widely.

Calculation of differential shortenings in high-rise buildings requires high degree of accuracy in analysis and usually obliges engineers to perform beyond the code based routine structural engineering calculations. In conventional modelling of reinforced concrete buildings, it is assumed that all floors of the structure are subjected to dead and live loads simultaneously. However, it is a fact that, dead loads of the structural elements and floors are applied in step by step manner to the previously constructed members during the progress of construction [1]. 
Behavior of a structure with the various loads applied in a single step differs significantly from that when the loads are applied in stages. Hence, in order to simulate the actual condition during the construction of the building, the building should be analyzed at every construction stage taking into account variation of loads [2]. The sequential application of dead loads has a great influence on the accuracy of the analysis results. Choi and Kim [3] were one of the frontiers and have stated that analysis of the entire structure could be obtained by one-substructure-at-a-time fashion by analyzing 10 -storey RC building. Since these procedures, however, require elaborated computations and more solution time, a simplified approach was proposed by Choi et al. [4] to solve the problem without elaborated step-by-step analysis. In their study, instead of carrying out the repetitive analysis, an approach that modifies the finite element analysis solution by adding or subtracting the correction forces calculated by the use of correction factors was proposed and 60 -storey RC building was investigated using the correction factor method.

As well as elastic deformations, axial deformations may occur due to time-dependent effects such as creep and shrinkage of concrete in multi-storey reinforced concrete buildings. The amount of shortenings for vertical members depends primarily upon the material characteristics, design parameters and loading parameters of the members. Material characteristics are modulus of elasticity, shrinkage, specific creep; design assumptions are cross-sectional area, volume-to-surface ratio, percentage of reinforcement; loading assumptions are progress of construction, progress of occupancy, environmental conditions such as temperature and humidity. Fintel et al. [5] proposed a procedure to predict column shortenings due to the time-dependent behavior and discussed the consequences of these effects briefly in their study. Likewise, a general prediction procedure was documented by the American Concrete Institute [6]. Accordingly, Gao and Bradford [7] proposed a method of analysis for the short-term and time-dependent response of slender, reinforced concrete columns using the age-adjusted effective modulus method. On the other hand, a practical approach based on incremental superposition method was presented by Pan et al. [8] for RC buildings up to 30 stories. Kwak and Kim [9] investigated construction sequence and time-dependent effects such as creep and shrinkage numerically and presented an effective solution procedure by using 10 -storey RC plane frame. Efficiency of their model was verified by comparison with results from previous analytical and experimental studies.
Their analysis results were summarized as; greater differential column shortenings and bending moments are developed when the construction sequence and the time-dependent deformations of concrete are considered; and greater serviceability problems in the non-structural members located between interior and exterior columns are induced by the differential column shortenings while the bending moments in beam members due to the column shortenings are not significant. For the purpose of developing a practical approach, Kim and Shin [10] had also studied a method in which stories were grouped and column shortening was considered with lumped construction sequences. It was stated that the proposed method which lumps more than two stories into one constructing unit yielded sufficiently close results to the exact model while it reduced the computing time remarkably. Although this approach provided reduction in computing time it was required to define some limits about lumped storey size. Kim et al. [11] had proposed a simplified analysis method with lumped construction sequences for the column shortening of tall buildings. In lumped construction sequence model, several building stories were lumped into one construction unit and the lumped units were assumed to be constructed at a time. The intention of the paper was investigating the effect and efficiency of lumped construction sequences on the column shortening and the internal forces of the horizontal members. Different arrangement methods for the lumped models and their advantages were also investigated. Kurc and Lulec [12], worked on construction sequences, time-dependent deformations and longitudinal reinforcement ratios by using several analysis approaches. A simplified model of an actual 37-storey building was used as a case study. Time dependent effects such as creep and shrinkage and the influence of modelling the longitudinal reinforcement considering axial load distribution were examined. The way the building was modelled and the type of analysis performed significantly influenced the axial loads and deformations of columns and walls. Besides, it was reported that shortening caused by creep and shrinkage significantly affected the amount of axial load carried by columns and shear walls. Creep was more effective in columns due to high compressive stresses, thus it was reported that a considerable amount of load was transferred from columns to shear walls. Kim et al. [13] outlined an improved column shortening analysis method that was aimed to be used at the design stage of tall buildings. This method considered construction sequences, the restraining effect of horizontal members, as well as creep and shrinkage. In the method, 
the whole analysis period was divided into two phases as before completion and after completion. It was underlined that the internal forces could be considerably overestimated due to the lack of reduction effects of the horizontal members to the differential shortening. For this reason, correction factors were introduced in the study and applied only to the before-completion phase to consider the gradual nature of construction sequences. Column shortenings of a 70-storey reinforced concrete frame-shear wall building were investigated as a numerical example. Kim et al. [13] also noted that their study improved the previous study presented by Choi and Kim [3] by considering the inelastic shortening due to creep and shrinkage. In order to be more practical and computer friendly, Kim [14] proposed an improved analysis method for column shortening of tall buildings based on a matrix analysis method of frames. The method was a step-by-step approach and it was applied for the exact displacement and internal forces for any elapsed time. Column shortenings of an 80-storey reinforced concrete frame-shear wall building were investigated as a numerical example and the analysis results showed that horizontal members, such as beams and outriggers, reduce the differential shortening between adjacent vertical members and that the stiffest beams achieve the greatest reduction in the differential shortening. However, it was noted that the internal forces in the horizontal members developed in proportion to the reduced differential shortenings. On the other hand, Afshari et al. [15] investigated the longterm behavior of special reinforced concrete moment frame structures in form of time-dependent shortening for 1000 days using different non-linear staged analyses. In their study, empirical equations were derived and the ranges of application of these equations were proposed using parametric studies and extensive modelling. Moreover, Afshari and Kheyroddin [16] improved aforementioned study by performing modelling and nonlinear staged analysis on structures with different geometrical characteristics and environmental conditions. They proposed semi-empirical equations to estimate vertical displacement of columns caused by creep, shrinkage for buildings up to 30 stories.

Studies that are based on time-dependent analysis are particularly focused on high-rise buildings in recent years. Li et al. [17] worked on the second tallest building in the world and the tallest in China with a structural height of $597 \mathrm{~m}$ and a total height of $660 \mathrm{~m}$ by a combined study of both on-site measurements and numerical analysis of the vertical deformations of the super tall building during its various construction stages. Results of the study revealed that a good agreement was found between the numerical results and the field measurements and it validated the influence of the time-dependent effects due to the construction sequence and the shrinkage and creep of concrete on the vertical deformations. Kim [18] investigated the effect of outrigger system on differential shortening in a tall building. Outrigger systems which are conventionally used to increase the lateral stiffness of the structural systems were considered and their effects on differential shortening of columns and walls were focused using 80 stories RC building. Optimum location of outrigger system was determined for reducing the differential shortening. Additionally, in order to enhance the applicability of the dual-purpose outrigger systems, Kim et al. [19] also investigated the amount of stress developed on the outrigger due to the reductions of the lateral displacement and differential axial shortening. On the other hand, Choi et al. [20] performed on-site measurements for determining column shortenings in a highrise building. The monitoring system was applied to actual $66^{\text {th }}$ floor and $72^{\text {nd }}$ floor of a 72-storey high-rise building for automatic and real-time measurements of the shortening of vertical members to achieve more precise construction. Alternatively, Pendharkar et al. [21] developed a neural network model for rapid prediction of the inelastic behavior. Indeed it was reported that the methodology presented in their study could be extended for further rapid prediction of inelastic deflections in high-rise frames in which the effect of axial shortening of the columns is significant.

Studies that are presented above are mainly focused on methods about determining the time-dependent behavior accurately rather using computational models or direct measurements on site. However, there are limited numbers of studies exist for improving the time-dependent structural behavior of high rise buildings based on compensation methods. Park [22] suggested a compensation method for the differential column shortening in a highrise building and formulated it as an optimization problem. A simulated annealing algorithm was used to find optimal solutions. The proposed method was applied to the compensation of the differential shortening of the vertical members in a 70-storey reinforced concrete building and 10 groups was determined as the number of groups required to have the optimum solution. Park et al. [23], proposed another method base on moving average correction method for compensation of differential column shortenings in high-rise buildings. In their study, the magnitude of the differential shortening in the vertical members was controlled without using any optimization technique. 
In this study, a new numerical compensation method was developed for differential shortening of vertical members. Optimal groups of vertical members were determined and total differences between member shortenings and group averages were minimized. A numerical example of 32-storey high-rise building from Izmir - Turkey was used to evaluate the efficiency of the developed algorithm by comparing the achieved results from uniform-grouped compensation results.

\section{Compensation methods}

Four types of compensation methods are generally used for differential shortening calculations of columns and shear walls of high-rise reinforced concrete buildings.

\subsection{Direct compensation method}

In direct compensation method, the amount of the correction value for a vertical member required at each floor level is predicted directly by the shortening at the floor level. In this manner, precise compensation can be performed with direct compensation method. However, direct compensation method requires different lengths of formworks for a vertical member at each level since required levels will be different at each floor level. Direct compensation method with the exact value of the correction for a vertical member at each floor level is a costly procedure. Also, it is not very practical and applicable for sites with high number of vertical members.

\subsection{Constant-average compensation method}

In constant-average compensation method, the correction amount for each floor is averaged by considering the total number of floors in the building. In this manner, all vertical members are increased by the same amount of correction for each floor level in order to minimize the number of different correction values in the compensation process. However, this method minimizes the use of different formwork but it introduces substantial differences between the predicted shortening values and the correction values after compensation.

\subsection{Uniform-grouped compensation method}

In order to use the advantages of previously mentioned methods, vertical members are grouped and the correction amount for each group is averaged considering the number of floors in the group. It can be recognized that if the number of groups become larger, the number of members in the groups become smaller and accordingly the differences gradually reduce.
The number of members that are grouped together in the uniform-grouped compensation method has direct influence on the efficiency of the compensation. Since the number of members in a group is equal for all groups, the number of groups is limited. On the other hand, if groups are formed with different numbers of members to achieve smaller shortening errors, groups are not uniform anymore. In this situation, an optimization technique is required to assign vertical members into groups efficiently.

\subsection{Optimal compensation method}

Optimization methods are used to find out the most effective and efficient solution to a specific problem among several solutions [24]. These methods have become very useful tools in various ranges of applications including to find optimal feature subset in pattern recognition applications $[25,26]$, optimal micro-structure parameters of a mechanical resonator design [27], optimal aerodynamic shape [28], optimal circuit elements for electrode design [29], and optimal path for mobile autonomous robots [30]. From the structural engineering point of view, optimization methods for differential shortenings of vertical members in highrise buildings aims to find the minimum number of vertical member groups by considering the practical applicability of the compensation process on site. Thus, magnitudes of the compensation errors are targeted to be minimized by optimization techniques. A detailed explanation and application of this method can be found in the literature [22].

\section{Penalized errors compensation method}

The first step of the optimization is finding a suitable error function. In studies related to compensation of member shortenings, the minimization of the greatest error in each group is added as a constraint to the optimization problem [22], which makes the problem more complex.

Especially in the machine learning literature, squared error (L2-norm) is preferred to penalize the bigger differences [31]. Thus, penalized errors compensation method was proposed in this study to exaggerate the effects of bigger values in the error function by eliminating the requirement of extra constraints.

The average correction value in the $\mathrm{i}^{\text {th }}$ group, $\delta_{i}^{c}$, can be calculated with Eq. (1).

$\delta_{i}^{c}=\frac{1}{N_{i}} \sum_{k=1}^{N_{i}} \delta_{k}^{p}$,

where $N_{i}$ is the number of members in the $\mathrm{i}^{\text {th }}$ group and $\delta_{k}^{p}$ is the predicted shortening value of the $\mathrm{k}^{\text {th }}$ members of the $i^{\text {th }}$ group. 
The error function can be defined as Eq. (2)

Minimize $\sum_{i=1}^{N_{g}} \sum_{k=1}^{N_{i}}\left|\delta_{i}^{c}-\delta_{k}^{p}\right|^{2}$,

with subject to Eq. (3)

Minimize $\left|\delta_{i}^{c}-\delta_{k}^{p}\right| \forall i, k$,

among all possible groupings.

Alternatively, in some special cases, absolute values (L1-norm) can also be used since this gives robust solutions. In a recent study, Moravec [30] presented a comprehensive comparison for both norms. L2-norm gives stable solutions but L1-norm never guarantees the stability. In addition, L2-norm always gives a unique solution although L1-norm may give multiple solutions. Consequently, both L1-norm and L2-norm of the differences between average corrections and predicted shortenings are investigated using the proposed penalized errors compensation method in this study. Their performances are examined by comparing to the results obtained by uniform-grouped compensation method.
In fact, direct and constant-average compensation methods are special cases of the proposed method. In the ideal case, these error functions generate 0 where the number of groups $\left(N_{g}\right)$ equals to the number of floors $(N)$ and the number of floors in each groups $\left(N_{i}\right)$ equals to 1 (i.e. assuming that every groups has only one floor), which equals to the direct compensation method. Likewise, this optimization method can evolve to the constant-average optimization method where the number of groups $\left(N_{g}\right)$ equals to 1 .

\subsection{Implementation of the proposed compensation method}

A 168-line code was developed in Matlab R2019a [32] to implement the proposed penalized errors compensation method with using L1-norm and L2-norm separately. The flowchart of the algorithm is given in Fig. 1 for L2-norm.

Proposed algorithm is repeated for the different number of groups from 1 to maximum number of groups $(\mathrm{NG})$ and their minimum errors with corresponding combination of members are reported. The maximum number of groups can be decided by analyzing the results. Since

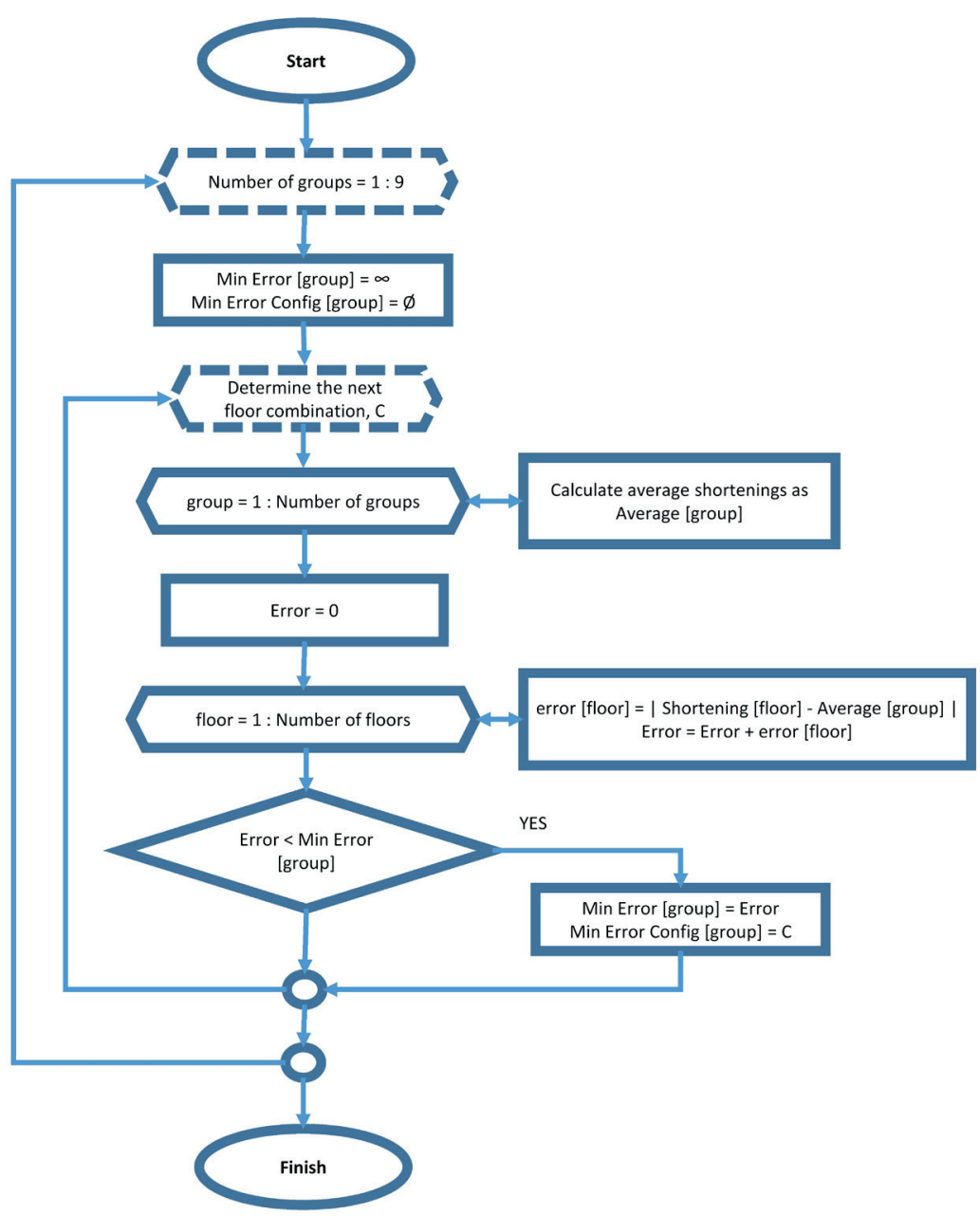

Fig. 1 Flowchart of the proposed penalized errors compensation method 
these analyses are time-consuming, limiting the number of groups is significant. Each group cycle starts with setting the minimum error as infinitive and the corresponding configuration is an empty set. Then, for each member configuration, the average compensation is calculated for each group. Next, the differences between average corrections and predicted shortenings are calculated as members' errors by using either L1-norm or L2-norm. Sum of these errors is the error of this configuration. If this error is less than aforementioned minimum error of the group, the error is set as the new minimum error and corresponding configuration is saved. This algorithm is repeated for all groups and configurations as a whole.

\section{Numerical example}

A high-rise reinforced concrete building that was built in Izmir - Turkey was used to investigate the time dependent behavior and construction sequence effects numerically. Reinforced concrete high-rise building consists of 32 total floors; 3 basements, 1 ground floor, and 28 typical floors. The total height of the building above the foundation including basements is $114.5 \mathrm{~m}$. Structural 3D model of the high-rise building was presented in Fig. 2 and the general features of the building were summarized in Table 1.

The typical floor plan for the tower part, column and shear wall labels were presented in Fig. 3 since the vertical members were in the focus of interest. Tower part has $35.3 \mathrm{~m} \times 18.4 \mathrm{~m}$ plan dimensions and it has $3.5 \mathrm{~m}$ floor-tofloor height.

There were 9 columns and 6 shear walls in the tower part and their floor levels, dimensions, reinforcements were summarized in Table 2.

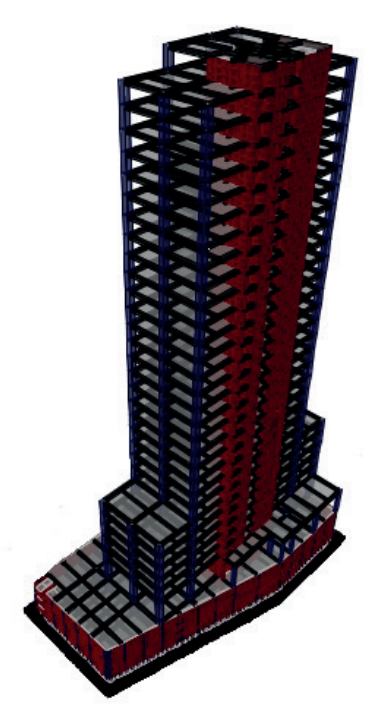

Fig. 2 High-rise reinforced concrete building model
Table 1 General information about high-rise building

\begin{tabular}{lc}
\hline Number of floors & 3 Basement + \\
& 1 Ground + \\
& 28 Normal \\
\hline Floor type & Floor height \\
$1^{\text {st }}$ basement & $3.50 \mathrm{~m}$ \\
$2^{\text {rd }}$ and $3^{\text {nd }}$ basement & $3.00 \mathrm{~m}$ \\
Ground floor & $7.00 \mathrm{~m}$ \\
$1-28$ typical floor & $3.50 \mathrm{~m}$ \\
Total building height & $114.50 \mathrm{~m}$ \\
Structural system & RC frames with shear walls \\
Concrete class & C40/50 \\
Reinforcement class & S420 \\
Partition walls & Aerated concrete blocks \\
Purpose of usage & Residence \\
Living Area & $2150 \mathrm{~m}^{2}$ \\
\hline
\end{tabular}

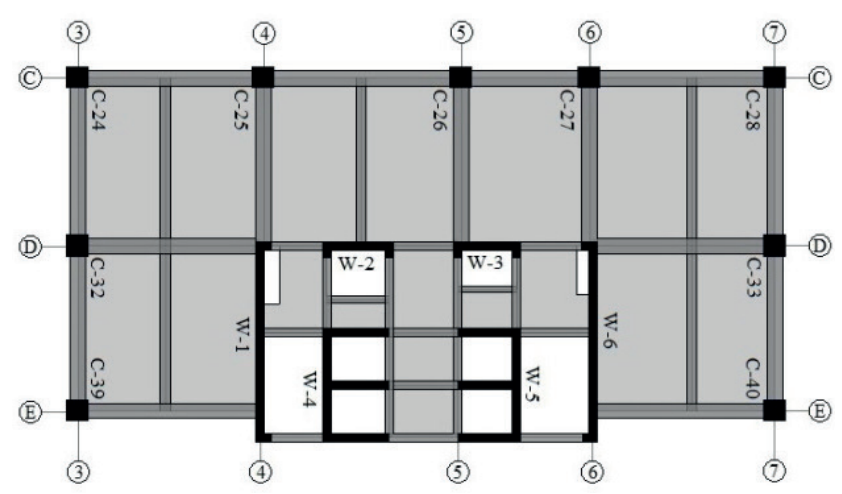

Fig. 3 Typical floor plan of the tower part of the high-rise building

In conventional analysis of reinforced concrete buildings, buildings are generally analyzed in a single step which is based on the assumption that buildings are subjected to full load when the construction is completed. In practice, dead loads due to the structural members are applied in separate stages as buildings are constructed storey by storey. There is a difference in the building behavior between the conventional approach that the loads are applied in one step and the approach that the construction steps are taken into consideration. Hence, in order to simulate the actual behavior during the construction of the building, non-linear construction sequence analysis was performed. In the numerical analysis, ETABS software [33] was used since many studies $[12,15,16]$ were accomplished successfully in the literature.

Likewise, time-dependent analyses are usually neglected in most of the conventional analysis. However, creep and shrinkage are substantial factors that affect differential shortenings of vertical members in high-rise buildings and for this reason; CEB-FIP 2010 Model Code [34] was used for time-dependent analyses. Time dependent creep 
Table 2 Column and shear wall dimensions and reinforcements of the tower part of the high-rise building

\begin{tabular}{|c|c|c|c|}
\hline $\begin{array}{l}\text { Member } \\
\text { Labels }\end{array}$ & Dimensions (cm) & Floors & Reinforcement \\
\hline \multirow{2}{*}{$\mathrm{C}-24, \mathrm{C}-28$} & $120 \times 120$ & $\begin{array}{l}3^{\text {rd }} \text { and } 2^{\text {nd }} \\
\text { basement }\end{array}$ & $40 \Phi 22$ \\
\hline & $110 \times 110$ & $\begin{array}{c}1^{\text {st }} \text { basement - } \\
28^{\text {th }} \text { floor }\end{array}$ & $32 \Phi 22$ \\
\hline \multirow{3}{*}{$\begin{array}{l}\text { C-25, C-26, } \\
\text { C-27 }\end{array}$} & $130 \times 130$ & $\begin{array}{l}3^{\text {rd }} \text { and } 2^{\text {nd }} \\
\text { basement }\end{array}$ & $48 \Phi 22$ \\
\hline & $120 \times 120$ & $\begin{array}{l}1^{\text {st }} \text { basement- } \\
5^{\text {th }} \text { floor }\end{array}$ & $40 \Phi 22$ \\
\hline & $110 \times 110$ & $\begin{array}{c}6^{\text {th }}-28 \text { th } \\
\text { floor }\end{array}$ & $32 \Phi 22$ \\
\hline \multirow{3}{*}{$\mathrm{C}-32, \mathrm{C}-33$} & $130 \times 130$ & $\begin{array}{l}3^{\text {rd }} \text { and } 2^{\text {nd }} \\
\text { basement }\end{array}$ & $48 Ф 22$ \\
\hline & $120 \times 120$ & $\begin{array}{l}1^{\text {st }} \text { basement - } \\
\text { ground floor }\end{array}$ & $40 \Phi 22$ \\
\hline & $110 \times 110$ & $1^{\text {st }}-28^{\text {th }}$ floor & $32 \Phi 22$ \\
\hline $\mathrm{C}-39, \mathrm{C}-40$ & $110 \times 110$ & $\begin{array}{c}3^{\text {rd }} \text { bas. }-28^{\text {th }} \\
\text { floor }\end{array}$ & $32 \Phi 22$ \\
\hline $\mathrm{W}-1, \mathrm{~W}-6$ & $990 \times 40$ & All floors & $94 \Phi 16,44 \Phi 14$ \\
\hline $\mathrm{W}-2$ & $350 \times 40$ & All floors & $68 Ф 14$ \\
\hline $\mathrm{W}-3$ & $330 \times 40$ & All floors & $58 \Phi 14$ \\
\hline W-4 & $(560+3 \times 310) \times 40$ & All floors & $\begin{array}{c}119 Ф 18, \\
64 Ф 14\end{array}$ \\
\hline W-5 & $(560+3 \times 290) \times 40$ & All floors & $\begin{array}{c}119 \Phi 18 \\
64 \Phi 14\end{array}$ \\
\hline
\end{tabular}

coefficient and shrinkage behavior can be defined using material properties of concrete such as; relative humidity percentage, cement type, starting age of shrinkage and notional thickness. In the numerical example, relative humidity was accounted as $50 \%$, cement type was PC42.5N, shrinkage starting age was considered as it had started with the member construction and notional thickness values for each column and shear wall segment were calculated by using $2 A_{c} / u$ relationship. In this relationship, $A_{c}$ is the area of member cross section and $u$ is the perimeter of the member in contact with the atmosphere. On the other hand, time-dependent effects assumed to be started with zero initial conditions to represent the unstressed state at the beginning of the construction and the construction period for each floor was accepted as 10 days. Besides, 3 more days are accounted before loading.

\subsection{Time-dependent analysis results}

High-rise reinforced concrete building was analyzed and linear static analysis, construction sequence analysis and time-dependent analyses results for C-25 column were

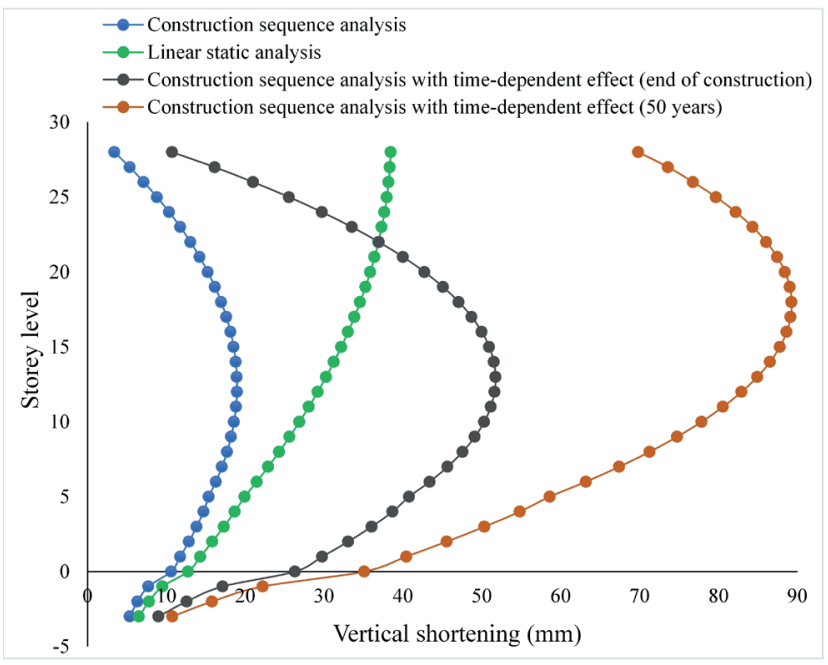

Fig. 4 Shortening of the C-25 column due to different types of analysis

plotted in Fig. 4. In time-dependent analyses, shrinkage and creep effects were considered at the end of construction period and at the end of 50 years period.

Linear elastic analysis results show that vertical shortening of C-25 column increased due to an increase in the number of storey levels as expected since all of the loads were assumed to be applied in a single step. However, construction sequence analysis results indicated that vertical displacements increased up to a floor level and afterwards vertical displacements decreased even the floor level increases. This can be explained in a simple manner that high axial loads and short total length exist in lower number of stories and lower axial loads and high total length exist in upper number of stories. On the other hand, Fig. 4 shows that time-dependent effects such as creep and shrinkage increased the vertical displacements significantly. Additionally, this analysis was repeated for all columns that were located in the tower part of the high-rise building and their time-dependent vertical displacements for 50 years were plotted in Fig. 5 .

Likewise, all shear walls of the tower part were considered and their time-dependent vertical displacements for 50 years were plotted in Fig. 6. Vertical displacements of shear walls were lower than the vertical displacements of columns.

\subsection{Compensation of vertical displacements}

The differential length changes of columns and shear walls in high-rise buildings due to elastic, creep and shrinkage shortenings may cause unexpected damages on structural and non-structural members. For this reason, the amount of correction for vertical members is required at each floor level and they can be evaluated for compensation. 


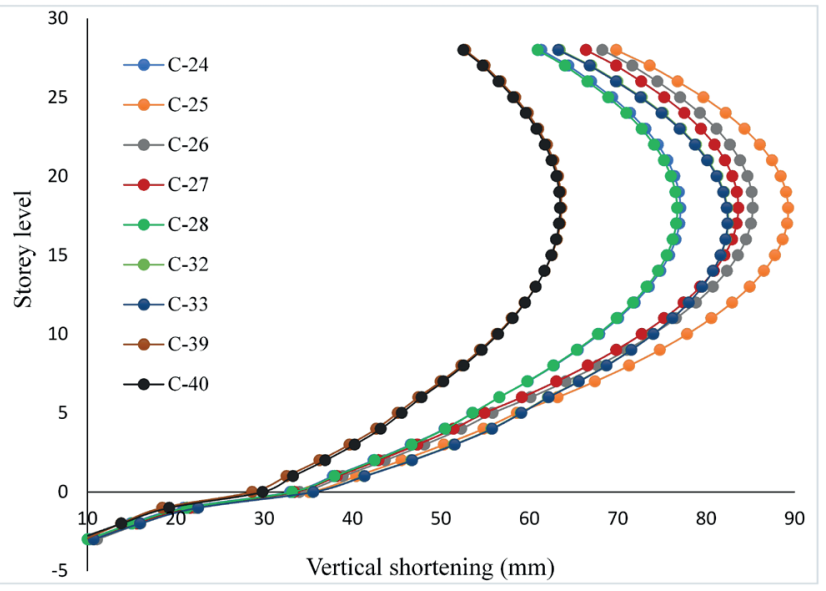

Fig. 5 Vertical shortening of all columns in the tower part

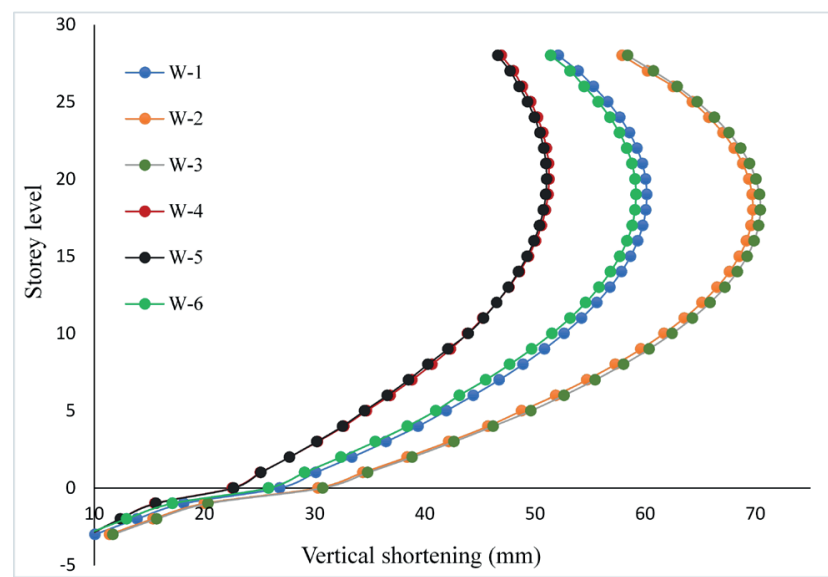

Fig. 6 Vertical shortening of all shear walls in the tower part

Differential shortenings of C-25 column were investigated in details and compensation methods were applied separately, since C-25 column made the maximum differential shortening among all vertical members. Uniformgrouped and the proposed penalized errors compensation method with using L1-norm and L2-norm were considered and their magnitudes of errors were compared. At first, uniform-grouped compensation method was applied with using 8 groups that had 4 members in each group. Accordingly, averages of each group were calculated and compensation for the column was determined accordingly. Analysis results for the differential shortenings of C-25 column using uniform-grouped compensation method were presented with Fig. 7.

Likewise, penalized errors compensation method with using L1-norm was applied to C-25 column and analysis results were presented with Fig. 8 .

Also, penalized errors compensation method with using L2-norm was applied to C-25 column and analysis results were presented with Fig. 9.

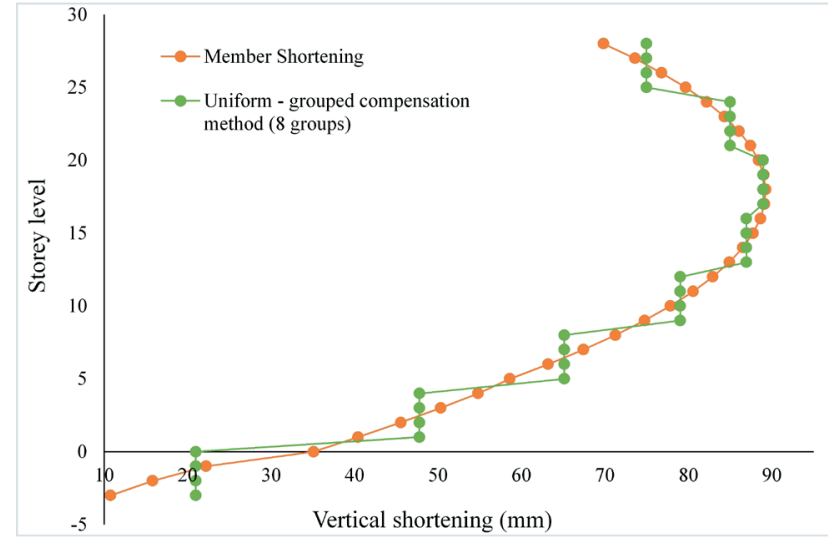

Fig. 7 Compensation curve considering the uniform-grouped compensation method for eight groups

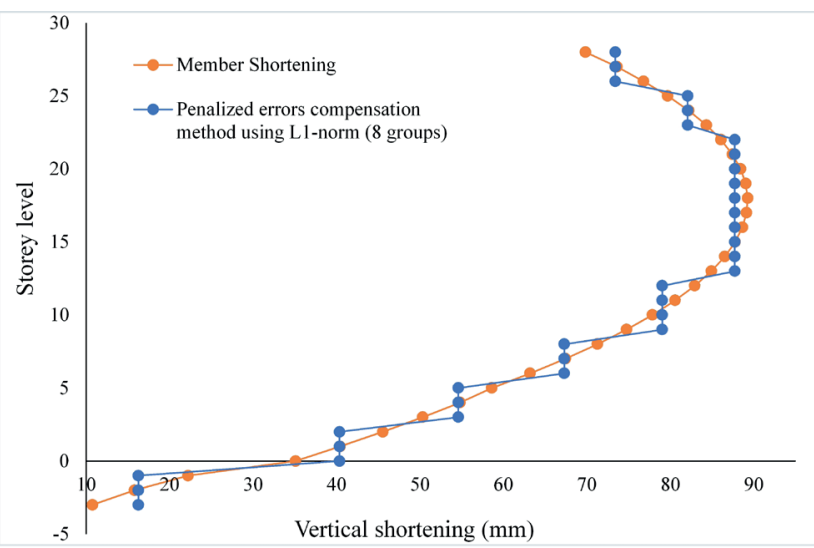

Fig. 8 Compensation curve considering the penalized errors compensation method with using L1-norm for eight groups

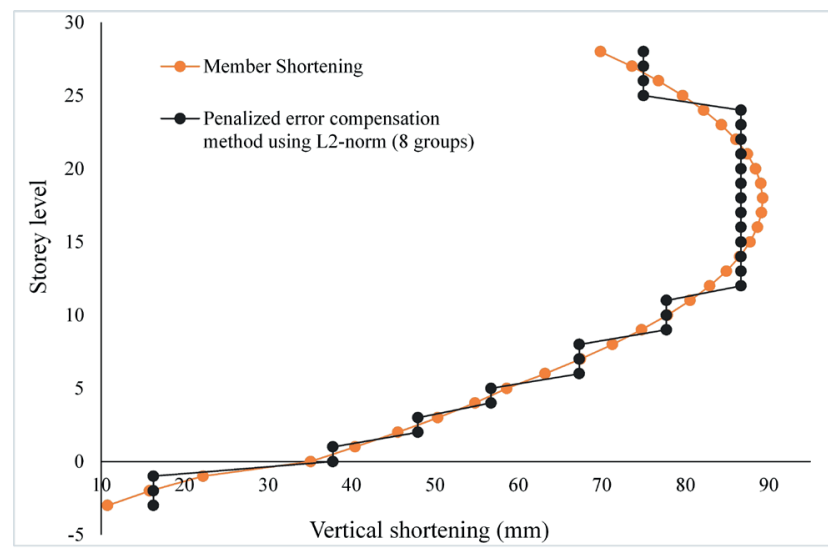

Fig. 9 Compensation curve considering the penalized errors compensation method with using L2-norm for eight groups

Comparison of compensation errors considering the uniform-grouped and the penalized errors compensation method with using L1-norm and L2-norm were performed for C-25 column for 8 groups. Number of groups was accounted as constant and same for evaluating the magnitude of errors of each compensation method. According 
to the methodology, only uniform-grouped compensation method had a fixed number of group members and in this case it was 4. Penalized errors compensation method with using L1-norm or L2-norm, had variable number of group members but the total number of groups was 8 . Analysis results showed that uniform-grouped compensation method give significantly higher errors than the other methods as shown in Fig. 10. Moreover, the proposed penalized errors compensation method results with using L1-norm and L2-norm were compared for eight groups. Analysis results revealed that error values are smaller when L2-norm is used.

In order to monitor the effects of number of groups, various analyses were performed for different number of groups for all columns in the tower part considering compensation methods. Since uniform-grouped compensation method uses uniform number of members in groups; 2,4 , 8 and 16 groups were formed with fixed number of group members as; 16, 8, 4 and 2 respectively. Maximum error and number of group relationships for all tower columns were determined using uniform-grouped compensation method in Fig. 11.

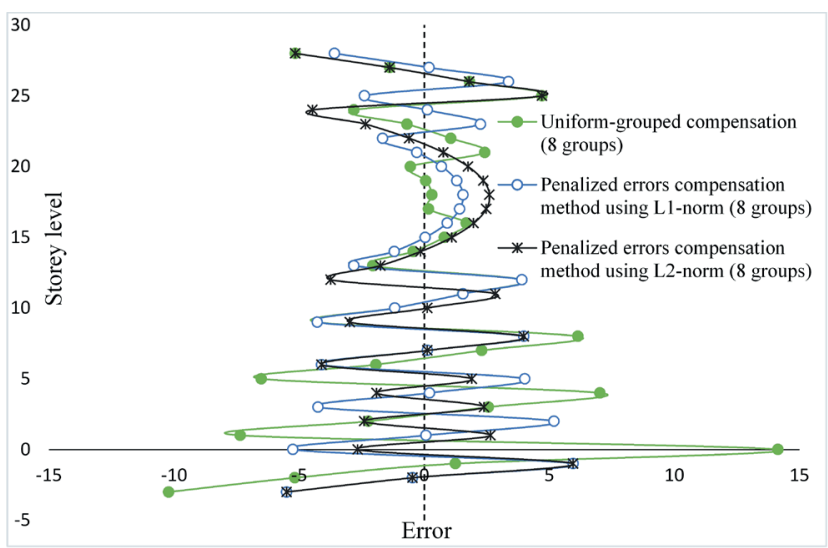

Fig. 10 Comparison of compensation errors considering the uniformgrouped and the penalized errors compensation method using L1-norm and L2-norm

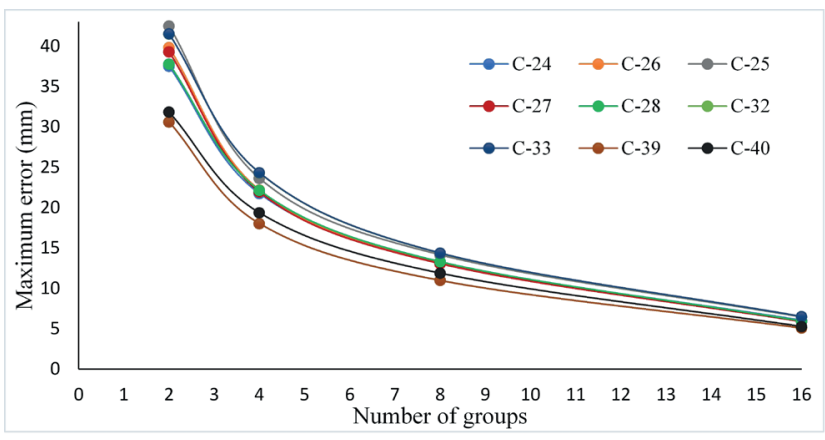

Fig. 11 Number of groups and compensation errors relationships for uniform-grouped compensation method for columns in the tower part
On the other hand, penalized errors compensation method with using L1-norm and L2-norm were applied for various numbers of groups. Grouping analysis for these methods stopped at number of 9 for the 32 storey building since the number of errors became low and stable. Maximum error and number of group relationships for all tower columns were presented for penalized errors compensation method using L1-norm and L2-norm in Fig. 12 and Fig. 13, respectively.

Likewise, maximum error and number of group relationships for all tower shear walls were presented using uniform-grouped, penalized errors compensation method with using L1-norm and L2-norm in Fig. 14, Fig. 15 and Fig. 16, respectively.

Compensation analyses results showed that maximum errors decreased as the number of group's increased for all columns and shear walls of the tower part. The proposed penalized errors compensation method with using L1-norm and L2-norm presented better performance than the uniform-grouped compensation method since numbers of the members in their groups were flexible and accordingly efficient groups were established.

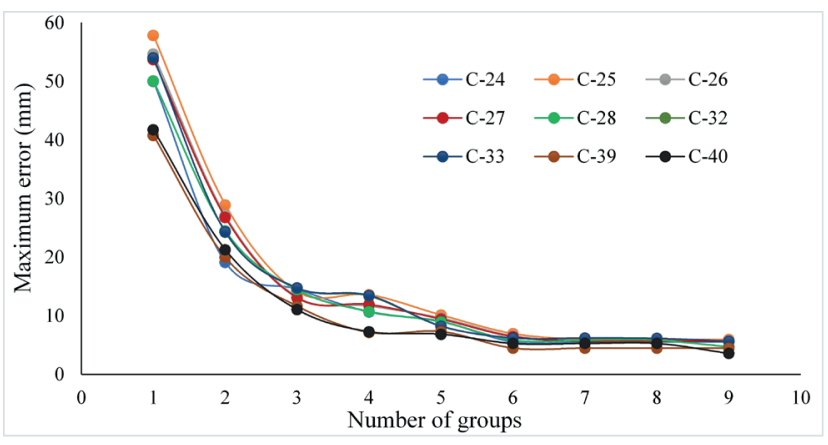

Fig. 12 Number of groups and compensation errors relationships for penalized errors compensation method using L1-norm for columns in the tower part

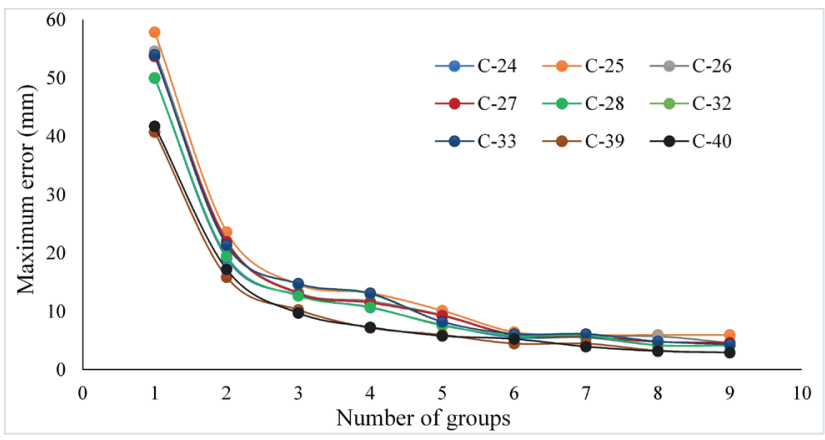

Fig. 13 Number of groups and compensation errors relationships for penalized errors compensation method using L2-norm for columns in the tower part 


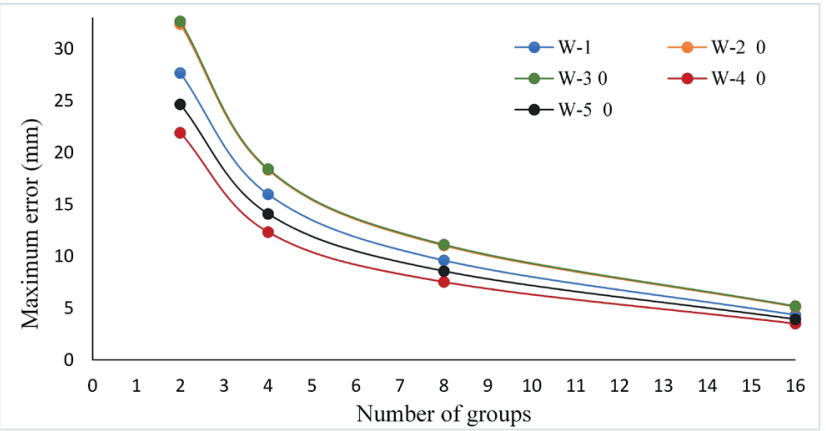

Fig. 14 Number of groups and compensation errors relationships for uniform-grouped compensation method for shear walls in the tower part

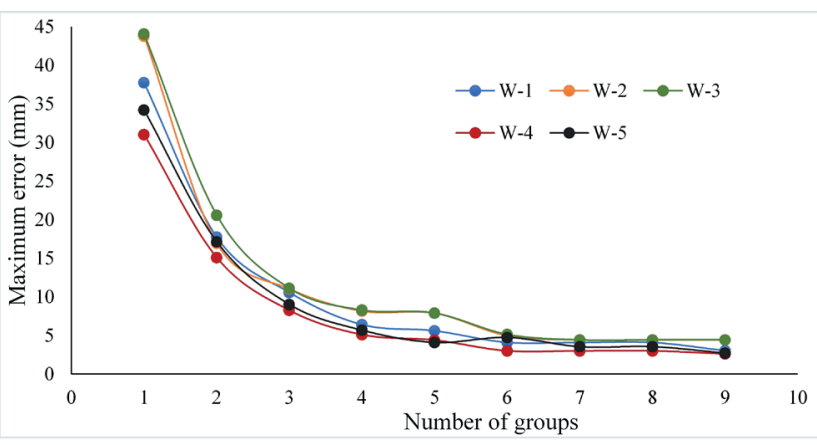

Fig. 15 Number of groups and compensation errors relationships for penalized errors compensation method with using L1-norm for shear walls in the tower part

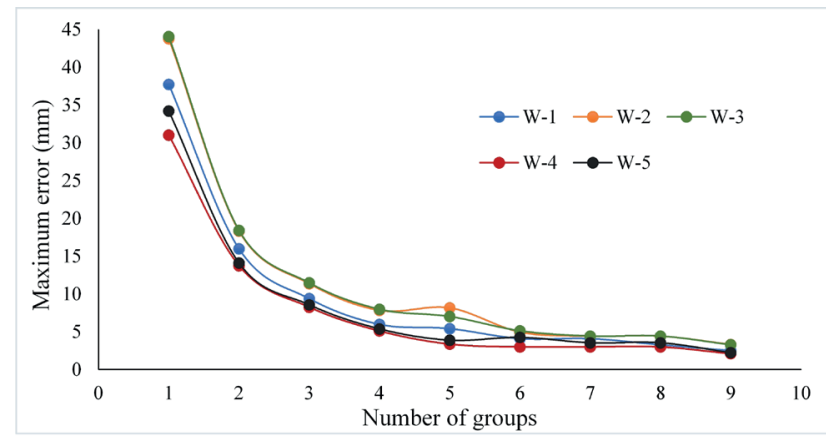

Fig. 16 Number of groups and compensation errors relationships for penalized errors compensation method with using L2-norm for shear walls in the tower part

Time required for these analyses were monitored considering the number of groups in penalized errors compensation method. Required time for each vertical member was calculated and their mean and standard deviation were presented for vertical members in Table 3.

As it can be noticed from Table 3, the required time increased tremendously with the increase in the number of groups. On the other hand, selecting high number of groups may introduce construction programming difficulties. Both of these concerns revealed the importance of selecting adequate number of groups for compensation in high-rise buildings.
Table 3 Calculation time for compensation of vertical members

\begin{tabular}{lc}
\hline Number of groups $(\mathrm{Ng})$ & $\begin{array}{c}\text { Calculation time for vertical members } \\
(\text { mean } \pm \text { standard deviation in seconds) }\end{array}$ \\
\hline 1 & $0.0892 \pm 0.0016$ \\
2 & $0.0902 \pm 0.0032$ \\
3 & $0.1284 \pm 0.0022$ \\
4 & $0.5420 \pm 0.0149$ \\
5 & $3.5815 \pm 0.0539$ \\
6 & $20.8805 \pm 0.4762$ \\
7 & $99.3688 \pm 2.8286$ \\
8 & $384.8728 \pm 6.9591$ \\
9 & $1278.6038 \pm 31.3292$ \\
\hline
\end{tabular}

Lastly, another compensation approach was performed by considering all columns of a storey together in the tower part and compensation groups were formed accordingly. In this approach, the proposed penalized errors compensation method was performed for all the columns of a storey together both using L1-norm and L2-norm separately. Since this approach aimed to consider compensation of all columns of a storey at the same time, the outcomes of the approach introduced relatively higher errors as shown in Table 4. Penalized errors compensation method with eight groups was used for comparison.

Likewise, compensation errors of shear walls were determined using penalized errors compensation method with eight groups for both approaches and results were presented in Table 5.

Considering all columns or shear walls in the tower part together introduced higher errors than considering these vertical members solely. Likewise, vertical members that

Table 4 Compensation errors of columns using penalized errors compensation method for different approaches (8 groups)

\begin{tabular}{|c|c|c|c|c|}
\hline \multirow[t]{3}{*}{$\begin{array}{l}\text { Label } \\
\text { of column }\end{array}$} & \multicolumn{2}{|c|}{$\begin{array}{l}\text { Considering } \\
\text { each column seperately } \\
\text { for compensation }\end{array}$} & \multicolumn{2}{|c|}{$\begin{array}{l}\text { Considering the } \\
\text { avarage of the } \\
\text { floor columns for } \\
\text { compensation }\end{array}$} \\
\hline & L1-norm & L2-norm & L1-norm & L2-norm \\
\hline & Max. Error & Max. Error & Max. Error & Max. Error \\
\hline C-24 & 5.5 & 4.2 & 5.7 & 5.0 \\
\hline C-25 & 6.0 & 6.0 & 13.6 & 13.3 \\
\hline C-26 & 5.7 & 5.7 & 10.7 & 10.7 \\
\hline C-27 & 5.6 & 4.8 & 8.9 & 8.9 \\
\hline C-28 & 5.8 & 4.2 & 5.8 & 5.4 \\
\hline C-32 & 6.1 & 4.8 & 9.0 & 8.9 \\
\hline C-33 & 6.1 & 4.8 & 9.1 & 9.0 \\
\hline C-39 & 4.5 & 3.3 & 17.7 & 16.6 \\
\hline C-40 & 5.3 & 3.2 & 17.6 & 16.5 \\
\hline Avarage & 5.6 & 4.6 & 10.9 & 10.5 \\
\hline
\end{tabular}


Table 5 Compensation errors of shear walls using penalized errors compensation method for different approaches ( 8 groups)

\begin{tabular}{|c|c|c|c|c|}
\hline \multirow[t]{3}{*}{$\begin{array}{l}\text { Label } \\
\text { of column }\end{array}$} & \multicolumn{2}{|c|}{$\begin{array}{l}\text { Considering } \\
\text { each column seperately } \\
\text { for compensation }\end{array}$} & \multicolumn{2}{|c|}{$\begin{array}{l}\text { Considering the } \\
\text { avarage of the floor } \\
\text { columns for compensation }\end{array}$} \\
\hline & L1-norm & L2-norm & L1-norm & L2-norm \\
\hline & Max. Error & Max. Error & Max. Error & Max. Error \\
\hline W-1 & 4.1 & 3.3 & 5.3 & 4.1 \\
\hline W-2 & 4.4 & 4.4 & 11.0 & 9.9 \\
\hline W-3 & 4.4 & 4.4 & 11.7 & 10.6 \\
\hline W-4 & 3.0 & 3.0 & 14.3 & 12.3 \\
\hline$W-5$ & 3.0 & 3.0 & 11.3 & 11.3 \\
\hline W-6 & 4.0 & 4.0 & 3.9 & 4.7 \\
\hline Avarage & 3.8 & 3.7 & 9.6 & 8.8 \\
\hline
\end{tabular}

had relatively lower errors for the case of considering all columns or shear walls together showed that these vertical members' behaviors were close to the average. However, considering all members together and applying compensation for a whole storey provides advantages in terms of construction technique.

\section{Conclusions}

In this study, a compensation method was proposed for the differential shortening of columns and shear walls in high-rise reinforced concrete buildings. Numerical analyses were performed and outcomes of the study can be summarized as follows.

- A high-rise building that consists of totally 32 floors was investigated considering construction sequence analysis, shrinkage and creep effects. Time-dependent analysis results for all columns and shear walls were presented and compensation methods were applied for determining the best compensation method by evaluating the magnitude of errors.

\section{References}

[1] Au, F. T. K., Liu, C. H., Lee, P. K. K. "Creep and shrinkage analysis of reinforced concrete frames by history-adjusted and shrinkage-adjusted elasticity moduli", The Structural Design of Tall and Special Buildings, 18(1), pp. 13-35, 2009.

https://doi.org/10.1002/tal.391

[2] Sharma, R. K., Maru, S., Nagpal, A. K. "Effect of beam stiffnesscolumn reinforcement on creep and shrinkage behaviour of R.C frames", The Structural Design of Tall and Special Buildings, 18(3), pp. 327-339, 2009. https://doi.org/10.1002/tal.422

[3] Choi, C.-K., Kim, E.-D. "Multistory Frames Under Sequential Gravity Loads", ASCE Journal of Structural Engineering, 111(11), pp. 2373-2384, 1985.

https://doi.org/10.1061/(ASCE)0733-9445(1985)111:11(2373)
- Comparison of compensation analysis results of all columns and shear walls revealed that uniform-grouped compensation method provided relatively high errors when it was compared with the proposed penalized errors compensation method.

- Additionally, penalized errors compensation method was applied with using L1-norm and L2-norm separately and relatively lower compensation errors were monitored for L2-norm.

- For all compensation methods, compensation errors generally decreased due to an increase in the number of groups. However, numerical analysis results of the investigated high-rise building show that increase in the number of groups more than eight did not improve the analysis results for penalized errors compensation method using L1-norm and L2-norm.

- The proposed penalized errors compensation method can also be used for determining the minimum number of groups that is required for compensation. Since computational time increases extremely for the increase in number of groups, determining the adequate number of groups become substantial both from computational and also constructional perspectives.

- The proposed compensation approach can be applied for any desired time period.

- Another compensation approach that considers vertical members of a storey together was also compared with the approach that considers vertical members separately using the proposed penalized errors compensation method. If vertical members are considered together for compensation, construction steps decrease clearly but compensation errors increase noticeably.

[4] Choi, C.-K., Chung, H.-K., Lee, D.-G., Wilson, E. L. "Simplified Building Analysis with Sequential Dead Loads-CFM", ASCE Journal of Structural Engineering, 118(4), pp. 944-954, 1992. https://doi.org/10.1061/(ASCE)0733-9445(1992)118:4(944)

[5] Fintel, M., Ghosh, S. K., Iyengar, H. "Column Shortening in Tall Buildings-Prediction and Compensation", Portland Cement Association, Skokie, IL, USA, 1984.

[6] ACI Committee "Prediction of Creep, Shrinkage, and Temperature Effects in Concrete Structures", American Concrete Institute, Detroit, MI, USA, Rep. ACI 209 R-82, 1992.

[7] Gao, Z., Bradford, M. A. "Time-Dependent Shortening of Slender RC Columns", ASCE Journal of Engineering Mechanics, 119(10), pp. 2036-2051, 1993. https://doi.org/10.1061/(ASCE)0733-9399(1993)119:10(2036) 
[8] Pan, L. B., Liu, P. C., Bakoss, S. L. "Long-Term Shortening of Concrete Columns in Tall Buildings", ASCE Journal of Structural Engineering, 119(7), pp. 2258-2262, 1993.

https://doi.org/10.1061/(ASCE)0733-9445(1993)119:7(2258)

[9] Kwak, H.-G., Kim, J.-K. "Time-dependent analysis of RC frame structures considering construction sequences", Building and Enviroment, 41(10), pp. 1423-1434, 2006.

https://doi.org/10.1016/j.buildenv.2005.05.013

[10] Kim, H. S., Shin, S. H. "Column Shortening Analysis with Lumped Construction Sequences", Procedia Engineering, 14, pp. 1791-1798, 2011.

https://doi.org/10.1016/j.proeng.2011.07.225

[11] Kim, H.-S., Jeong, S.-H., Shin, S.-H. "Column shortening analysis of tall buildings with lumped construction sequences", The Structural Design of Tall and Special Buildings, 21(10), pp. 764-776, 2012. https://doi.org/10.1002/tal.650

[12] Kurc, O., Lulec, A. "A comparative study on different analysis approaches for estimating the axial loads on columns and structural walls at tall buildings", The Structural Design of Tall and Special Buildings, 22(6), pp. 485-499, 2013.

https://doi.org/10.1002/tal.699

[13] Kim, H.-S., Jeong, S.-H., Shin, S.-H., Park, J.-P. "Simplified column shortening analysis of a multi-storey reinforced concrete frame", The Structural Design of Tall and Special Buildings, 21(6), pp. 405$415,2012$.

https://doi.org/10.1002/tal.607

[14] Kim, H.-S. "Effect of horizontal members on column shortening of reinforced concrete building structures", The Structural Design of Tall and Special Buildings, 22(5), pp. 440-453, 2013. https://doi.org/10.1002/tal.696

[15] Afshari, M. J., Kheyroddin, A., Gholhaki, M. "Simplified TimeDependent Column Shortening Analysis in Special Reinforced Concrete Moment Frames", Periodica Polytechnica Civil Engineering, 62(1), pp. 232-249, 2018.

https://doi.org/10.3311/PPci.10679

[16] Afshari, M. J., Kheyroddin, A. "A Predicting Method for Long-Term Behavior of Reinforced Concrete Moment Frames", ACI Structural Journal, 116(6), pp. 195-211, 2019.

https://doi.org/10.14359/51718007

[17] Li, Q., He, Y., Wang, H., Zhou, K., Yan, B. "Monitoring and time-dependent analysis of vertical deformations of the tallest building in China", Structural Control Health Monitoring, 24(7), Article ID: e1936, 2017.

https://doi.org/10.1002/stc.1936

[18] Kim, H.-S. "Effect of Outriggers on Differential Column Shortening in Tall Buildings", International Journal of High-Rise Buildings, 6(1), pp. 91-99, 2017. https://doi.org/10.21022/IJHRB.2017.6.1.91

[19] Kim, H.-S., Lim, Y.-J., Lee, H.-L. "Strength demand of dual-purpose outrigger system for reducing lateral displacement and differential axial shortening in a tall building", The Structural Design of Tall and Special Buildings, 29(4), Article ID: e1701, 2020. https://doi.org/10.1002/tal.1701
[20] Choi, S. W., Kim, Y., Kim, J. M., Park, H. S. "Field Monitoring of Column Shortenings in a High-Rise Building during Construction", Sensors, 13, pp. 14321-14338, 2013.

https://doi.org/10.3390/s131114321

[21] Pendharkar, U., Patel, K. A., Chaudhary, S., Nagpal, A. K. "Rapid Prediction of Moments in High-rise Composite Frames Considering Cracking and Time-effects", Periodica Polytechnica Civil Engineering, 61(2), pp. 282-291, 2017. https://doi.org/10.3311/PPci.8210

[22] Park, H. S. "Optimal compensation of differential column shortening in high-rise buildings", The Structural Design of Tall and Special Buildings, 12(1), pp. 49-66, 2003. https://doi.org/10.1002/tal.212

[23] Park, S. W., Choi, S. W., Park, H. S. "Moving average correction method for compensation of differential column shortenings in highrise buildings", The Structural Design of Tall and Special Buildings, 22(9), pp. 718-728, 2013.

https://doi.org/10.1002/tal.722

[24] Glandt, E. D., Klein, M. T., Edgar, T. E. "Optimization of chemical processes", McGraw-Hill Higher Education, 2nd ed., New York, NY, USA, 2001.

[25] Narin, A., Isler, Y., Ozer, M., Perc, M. "Early prediction of paroxysmal atrial fibrillation based on short-term heart rate variability", Physica A: Statistical Mechanics and its Applications, 509, pp. 56-65, 2018.

https://doi.org/10.1016/j.physa.2018.06.022

[26] Narin, A., Isler, Y., Ozer, M. "Investigating the performance improvement of HRV Indices in CHF using feature selection methods based on backward elimination and statistical significance", Computers in Biology and Medicine, 45, pp. 72-79, 2014. https://doi.org/10.1016/j.compbiomed.2013.11.016

[27] He, W., Bindel, D., Govindjee, S. "Topology optimization in micromechanical resonator design", Optimization and Engineering, 13, pp. 271-292, 2012. https://doi.org/10.1007/s11081-011-9139-1

[28] Gauger, N., Walther, A., Özkaya, E., Moldenhauer, C. "Efficient aerodynamic shape optimization by structure exploitation", Optimization and Engineering, 13, pp. 563-578, 2012. https://doi.org/10.1007/s11081-011-9184-9

[29] Zhou, D., Sharma, S. K., Lüttgen, A., Sarris, C. D. "Systematic Design Optimization of Capacitive Touch Sensor Electrode Patterns", IEEE Sensors Journal, 20(4), pp. 1962-1970, 2020. https://doi.org/10.1109/JSEN.2019.2948893

[30] Moravec, J. "A Comparative Study: L1-Norm Vs. L2-Norm; Pointto-Point Vs. Point-to-Line Metric; Evolutionary Computation Vs. Gradient Search", Applied Artificial Intelligence, 29(2), pp. 164$210,2015$. https://doi.org/10.1080/08839514.2015.993560

[31] Duda, R. O., Hart, P. E., Stork, D. G. "Pattern Classification", 2nd ed., Wiley, New York, NY, USA, 2000.

[32] MathWorks "Matlab R2019a", [computer program] Available at: https://www.mathworks.com/videos/release-2019a-highlights1551299250379.html [Accessed: 06 March 2020] 
[33] Computer and Structures "ETABS Integrated Building Design Software, Technical Reference Manual", Computer and Structures Inc., Berkeley, CA, USA, 2019

[34] fib "fib Model Code for Concrete Structures 2010", Federation for Structural Concrete (fib), Ernst \& Sohn, Berlin, Germany, 2013. https://doi.org/10.1002/9783433604090
[35] ACI "ACI 318-14 Building Code Requirements for Structural Concrete and Commentary", American Concrete Institute, Farmington Hills, MI, USA, 2014, [online] Available at: https://www.concrete.org/store/productdetail.aspx?ItemID= 318U14\&Language $=$ English 